\title{
Organic-inorganic nanocomposites prepared by reactive suspension method: investigation on filler/matrix interactions and their effect on the nanoparticles dispersion
}

\author{
Alberto Spinella ${ }^{1}$ - Federica Bondioli ${ }^{2}$ Giorgio Nasillo ${ }^{1}$ • Vincenzo Renda ${ }^{3}$. \\ Eugenio Caponetti ${ }^{1,3}$ - Massimo Messori ${ }^{4}$ - Davide Morselli ${ }^{5}$ (I)
}

Received: 9 December 2016 / Revised: 18 January 2017 / Accepted: 28 January 2017

(C) Springer-Verlag Berlin Heidelberg 2017

\begin{abstract}
Epoxy resin/ $/ \mathrm{TiO}_{2}$ nanocomposites prepared by both reactive suspension method, based on in situ synthesis, and conventional mechanical mixing are analysed by solidstate nuclear magnetic resonance and transmission electron microscopy in order to have a deeper insight into the nature of interactions at the polymer/particle interface and their effect on the nanoparticles dispersion. Specifically, solid-state nuclear magnetic resonance experiments showed that the nanoparticles, synthesized by reactive suspension method, can efficiently link the matrix by hydrogen bonds forming a hybrid organic-inorganic 3D network. Such evidences strongly supports our previously reported theory, in which the nanoparticles in situ synthesized by reactive suspension method act not only as rigid filler, but also as actual cross-linking points, dramatically improving the mechanical properties of the polymeric matrix. Moreover, as revealed by transmission electron microscopy investigations, the formation of such hydrogen
\end{abstract}

Federica Bondioli

federica.bondioli@unipr.it

$\triangle$ Davide Morselli

davide.morselli@iit.it

1 Centro Grandi Apparecchiature (CGA) - ATeN Center, Università di Palermo, Via Filippo Marini 14, 90128 Palermo, Italy

2 Department of Engineering and Architecture, Università degli Studi di Parma, Parco Area delle Scienze 181/A, 43124 Parma, Italy

3 Department of Biological, Chemical, and Pharmaceutical Sciences and Technologies (STEBICEF), Università di Palermo, Viale delle Scienze ed. 17, 90128 Palermo, Italy

4 Department of Engineering "Enzo Ferrari”, Università degli Studi di Modena e Reggio Emilia, Via Pietro Vivarelli 10/1,

41125 Modena, Italy

5 Smart Materials, Nanophysics Department, Istituto Italiano di Tecnologia, Via Morego 30, 16163 Genoa, Italy bonds significantly affect also the nanoparticles distribution, thanks to a stabilizing effect on the nanoparticles' surface that prevents their aggregation and improves their dispersion.

Keywords Reactive suspension method $\cdot$ Hybrid nanocomposite $\cdot \mathrm{H}$-bonds $\cdot$ Nanoparticles/polymer interface . Dispersion

\section{Introduction}

Since the second half of the last century, polymer-based hybrid composites became widely used materials being lightweight and cost-effective, which also attracts the interest of the industrial world. In particular, the incorporation of inorganic oxides in polymeric matrices has been a very simple method in order to obtain higher stiffness [1] or to improve solvent [2] and fire resistance. [3] Nowadays $\mathrm{Al}_{2} \mathrm{O}_{3}$, [4] $\mathrm{SiO}_{2}$, [5] $\mathrm{TiO}_{2},[6] \mathrm{ZrO}_{2}$ [7] and $\mathrm{ZnO}$ [8] nanoparticles (NPs) represent the most commonly used inorganic filler, inducing significant reinforcing and stiffening effects to the hosting polymeric matrix. Indeed, the filler/matrix adhesion, filler dimensions, dispersion and content play important roles in the final mechanical properties of the composites. [9] The effects of the above-mentioned parameters on the polymer mechanical properties were carefully reviewed by $\mathrm{Fu}$ et al. [10], who concluded that the composite strength and toughness are mainly affected by the particle/matrix adhesion, expanding a former study by Ou et al. [11]. Moreover, regarding the effect on Young's modulus, a critical particle size was determined. Below this value, that cannot be predicted a priori, the composite stiffness is significantly affected by the filler particle size, due to the much larger surface areas that impart the socalled "nano-effect" [10]. In this regard, one of the main problems related to nanocomposites is the effective dispersion of 
the NPs in the polymer matrix [12]. For instance, Ou and coworker showed that when the content of silica in Nylon 6 is above $5 \mathrm{wt} \%$, the particle aggregation occurs, leading to a decrement of the composite tensile strength and elongation at break [11]. In order to overcome this typical drawback, the authors have optimized a procedure, only recently called reactive suspension method ( $R S$ method), which is based on the in situ synthesis of oxide NPs in polymeric matrices. Such method allowed obtaining homogeneous filler dispersion (i.e. $\left.\mathrm{TiO}_{2},[13-18] \mathrm{Fe}_{3} \mathrm{O}_{4},[19,20]\right)$ in different polymeric matrices (i.e. poly(methyl methacrylate) and epoxy resins). Specifically, the proposed approach combines a nonhydrolytic sol-gel (NHSG) reaction, [21] used for obtaining a reactive NP suspension, and a cationic polymerization capable to polymerize the residual solvent and monomer as part of the same matrix [22]. By means of this facile two-step method, it is possible to prepare crystalline NPs homogeneously dispersed in a polymeric matrix without requiring timeconsuming separation and purification steps and/or functionalization procedures, with the possibility to achieve high filler contents and low aggregation. Regarding the mechanical properties of the so-obtained nanocomposites, the trend is comparable with that one reported by $\mathrm{Fu}$ and coworkers [10]. In particular, epoxy resin/ $/ \mathrm{TiO}_{2}$ nanocomposites, prepared by $R S$ method, showed an unusual remarkable enhancement of the glass transition temperature $\left(T_{\mathrm{g}}\right)$ and storage modulus (E') especially in the rubbery region [13]. However, comparing the measured $\mathrm{E}^{\prime}$ moduli to the theoretical ones, predicted by Kerner equation [23], an unexpected and significant discrepancy was observed [14]. The experimentally obtained values were remarkably higher than both Kerner equation prediction and values reported by $\mathrm{Fu}$ and co-worker, even taking into account the reported "nano-effect" [10]. In our previous studies [13-15], such behaviour had always been ascribed to the formation of a very strong interaction at the particle/matrix interface, which makes filler NPs acting as a sort of additional cross-linking points. However, the abovedescribed particles/matrix interaction has never been directly observed, but it was reasonably assumed by comparing the $\mathrm{E}^{\prime}$ in the rubbery region of the neat resin and epoxy resin/ $/ \mathrm{TiO}_{2}$ nanocomposites $[13,14]$. It is well known that $\mathrm{E}^{\prime}$ of a crosslinked polymeric matrix (such as vulcanized elastomers) is mainly governed by the cross-linking density in the rubbery state, therefore it is plausible to suppose that those particles act not only as a rigid filler (as considered by Kerner equation and Fu's study), but also as an actual cross-linking point $[13,14]$. In addition, some theoretical calculations of the average molecular weight between two cross-linking points strongly support this idea [15].

In the present work, epoxy resin/ $/ \mathrm{TiO}_{2} \mathrm{NPs}$ prepared by both $R S$ method and conventional mixing method were investigated by solid-state nuclear magnetic resonance (ss-NMR) and transmission electron microscopy to have a deeper insight into the nature of the interactions at the particle/polymer interface and their effect on the NP dispersion for supporting the previously reported results with direct experimental evidences.

\section{Experimental}

\section{Materials}

3,4-Epoxycyclohexylmethyl 3,4-epoxycyclohexanecarboxylate (CE), titanium(IV) chloride $\left(\mathrm{TiCl}_{4}\right)$, benzyl alcohol $(\mathrm{BzOH})$, propylene carbonate (PC), ytterbium(III) trifluoromethanesulfonate hydrate $\left(\mathrm{Yb}(\mathrm{OTf})_{3}\right)$, chloroform, acetone, ethanol and diethyl ether were purchased from Sigma Aldrich (Milan, Italy). All chemicals were high purity reactants and were used as received without any further purification.

\section{Nanocomposites preparation}

According to the previously reported synthesis procedure [14], $0.59 \mathrm{~g}$ of $\mathrm{TiCl}_{4}$ was added dropwise to $1.50 \mathrm{~g}$ of $\mathrm{BzOH}$ at room temperature under vigorous stirring. The reaction solution was left stirring at room temperature for $15 \mathrm{~min}$ and afterwards, it was heated at $70{ }^{\circ} \mathrm{C}$ for $24 \mathrm{~h}$, by oil bath. The so-obtained stable titania suspension was mixed with $5 \mathrm{~g}$ of $\mathrm{CE}$ epoxy resin and $0.15 \mathrm{~g}$ of $\mathrm{Yb}(\mathrm{OTf})_{3} / \mathrm{PC}(1: 3 \mathrm{wt} / \mathrm{wt})$ solution, as thermal cationic initiator, by a T18 Ultra-T2 TurraxVR Ika disperser ( 5 min mixing time) followed by 15 min treatment in an ultrasonic bath operating at $59 \mathrm{kHz}$ (LBS 2, Falc). The formulation was cast then into silicone moulds (cavity dimensions of $4 \times 1 \times 0.5 \mathrm{~cm}^{3}$ ) and degassed for $15 \mathrm{~min}$ by dynamic vacuum in order to avoid bubbles formation in the final samples. Finally, the formulation was cured at $120^{\circ} \mathrm{C}$ for $25 \mathrm{~min}$ and post-cured at $160^{\circ} \mathrm{C}$ for further $20 \mathrm{~min}$. The soobtained material was coded as CE-T5.

According to the so-called ex situ synthesis procedure [14], composites were also prepared by conventional mechanical mixing of the ex situ synthesized titania NPs through NHSG reaction [14]. The powder was centrifuged at $4000 \mathrm{rpm}$ for $15 \mathrm{~min}$ and carefully washed twice using chloroform, twice with acetone and once with diethyl ether, sonicating for 10 min every time that fresh solvent was added. The washed $\mathrm{TiO}_{2}$ powder was dried at $60{ }^{\circ} \mathrm{C}$ for $8 \mathrm{~h}$ under dynamic vacuum. Titania NPs were used both as obtained and after calcination in air at $500{ }^{\circ} \mathrm{C}$ for $5 \mathrm{~h}$ in order to eliminate the organic substances and hydroxyl groups (titanols) present on the particles' surface. The composite materials prepared by ex situ $\mathrm{TiO}_{2}$ NPs were cured using the same conditions, described above for CE-T5. The so-prepared composites were coded as CE-T5-ex and CE-T5-ex-C (calcined $\mathrm{TiO}_{2}$ ), respectively. 


\section{Nanocomposites characterization}

The ${ }^{13} \mathrm{C}$ cross polarization-magic angle spinning nuclear magnetic resonance $\left({ }^{13} \mathrm{C}\left\{{ }^{1} \mathrm{H}\right\}\right.$ CP-MAS NMR) spectra, of the prepared samples, were acquired at room temperature with a Bruker Avance II $400 \mathrm{MHz}(9.4 \mathrm{~T}$ ) spectrometer, operating at 100.63 and $400.15 \mathrm{MHz}$ for both ${ }^{13} \mathrm{C}$ and ${ }^{1} \mathrm{H}$ nuclei. All experiments were performed with a MAS rate of $6.5 \mathrm{kHz}, 1024$ scans, contact time of $1.5 \mathrm{~ms}$, delay time of $2 \mathrm{~s}$ and an excitation pulse on the nuclide ${ }^{1} \mathrm{H} 4.35 \mu \mathrm{s}$. The optimization of the Hartmann-Hahn condition [24] was obtained using an adamantane standard that was also used as external chemical shift reference (29.5 and $38.6 \mathrm{ppm}$ ). All samples were grinded and placed in 4-mm zirconia rotors that were sealed with Kel$F ®$ caps using silica as a filler to prevent inhomogeneity inside the rotor.

The carbon spin-lattice relaxation times in the rotating frame $\left(\mathrm{T}_{1 \rho} \mathrm{C}\right)$ were determined with the variable spin lock (VSL) pulse sequence [25] using delay times ranging from 0.4 to $30 \mathrm{~ms}$ and a contact time of $1.5 \mathrm{~ms}$.

The cross-polarization time $\left(T_{\mathrm{CH}}\right)$ and the proton spin-lattice relaxation time in the rotating frame $\left(\mathrm{T}_{1 \rho} \mathrm{H}\right)$ values were obtained through variable contact time (VCT) experiments [26], using contact times ranging from 0.05 to $7.0 \mathrm{~ms}$.

The samples for transmission electron microscopy (TEM) investigations were prepared by cutting $100 \mathrm{~nm}$ thick slices by a Leica EM UC6 ultracryomicrotome. The so-obtained slices were placed onto 3-mm copper grids Lacey Carbon Films (200 Mesh) and analysed with a Jeol JEM 2100 operating at $120 \mathrm{kV}$ to avoid the sample degradation due to electron radiation.

\section{Results and discussion}

${ }^{13} \mathrm{C}\left\{{ }^{1} \mathrm{H}\right\}$ CP-MAS NMR spectra, in Fig. 1, present four broad signals. The resonance between 16 and $50 \mathrm{ppm}$ is due to the cycloaliphatic carbons non-bonded to an oxygen atom $\left(\mathrm{C}_{\mathrm{A}}\right)$ [27], while the signal between 60 and $90 \mathrm{ppm}$ is attributed to the overlap $\left(\mathrm{C}_{\mathrm{B}+\mathrm{B}^{\prime}}\right)$ of the resonances of the aliphatic rings' carbons $\left(\mathrm{C}_{\mathrm{B}}\right)$ bonded to oxygen atoms and of the $\mathrm{CH}_{2}\left(\mathrm{C}_{\mathrm{B}^{\prime}}\right)$ of the ester group [27]. The most deshielded signal at $175 \mathrm{ppm}$ is due to the carbonyl carbon $\left(C_{C}\right.$ in Fig. 1) [27], whereas the resonance between 120 and $140 \mathrm{ppm}$, present in all the spectra, is probably due to the aromatic carbons of the $\mathrm{BzOH}$. No significant differences in the chemical shift among the signals of the pure epoxy resin and the nanocomposites were detected. This indicates that the filler does not cause any chemical modification of the polymeric matrix. Besides, no spectrum shows the typical resonance at $55 \mathrm{ppm}$ due to epoxy rings [27], hence ensuring high curing degree of the epoxy resin also in presence of the filler, in good agreement to formerly reported results [13].
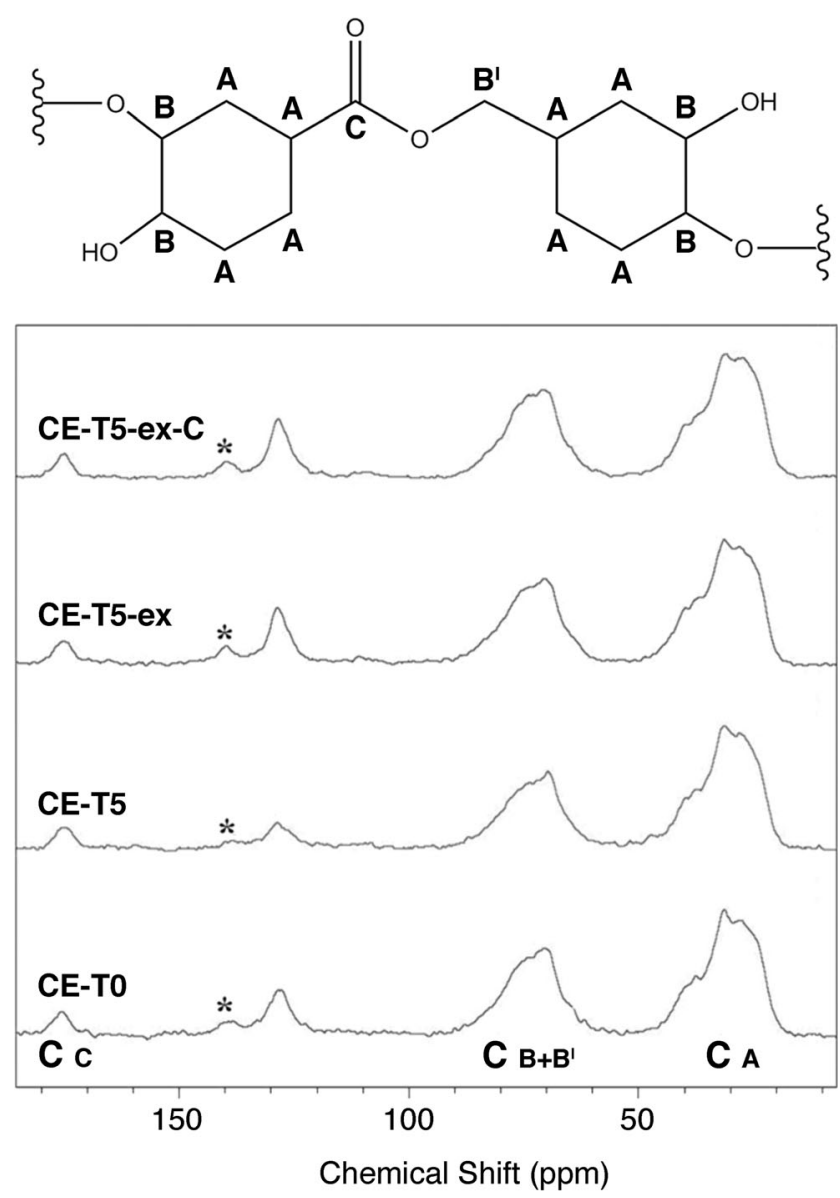

Fig. 1 Epoxy monomer formula (upper side) and ${ }^{13} \mathrm{C}\left\{{ }^{1} \mathrm{H}\right\}$ CP-MAS NMR spectra of the analysed samples and related carbon assignments (asterisk indicates spinning sidebands)

In order to have a deeper insight on the filler/epoxy resin interactions, the systems were also investigated by ss-NMR relaxometry. Both $\mathrm{T}_{1 \rho} \mathrm{C}$ and $\mathrm{T}_{1 \rho} \mathrm{H}$ were determined for obtaining information about the molecular motions in the $\mathrm{kHz}$ range. In particular, $\mathrm{T}_{1 \rho} \mathrm{C}$ is a probe of local motions [28-31], while $\mathrm{T}_{1 \rho} \mathrm{H}$ provides overall information on motions of the whole polymer chains. Involving a large number of monomeric units, $\mathrm{T}_{1 \rho} \mathrm{H}$ is significantly affected by the spin diffusion process, which tends to average it to a single mean value [32].

An increase of the $\mathrm{T}_{1 \rho} \mathrm{C}$ values (in Table 1) for both $\mathrm{C}_{\mathrm{A}}$ and $\mathrm{C}_{\mathrm{B}+\mathrm{B}^{\prime}}$ signals is observed for the nanocomposites compared to the unfilled epoxy resin, indicating a slowing effect on the molecular motions at the local level, due to the inhibition of the inversion process of the cyclohexyl rings. Such stiffening effect, at the molecular level, may be correlated at macroscopic level to both $T_{\mathrm{g}}$ and to the E' modulus enhancement, previously reported for nanocomposite prepared by $R S$ method $[13-15,33]$. This idea is then further supported by the observed increase of $\mathrm{T}_{1 \rho} \mathrm{H}$ values (in Table 2), which is evident in presence of the filler. Such increase of $T_{1 \rho} \mathrm{H}$ indicates that the molecular motions, associated to the cooperative polymer 
Table $1 \mathrm{~T}_{1 \rho} \mathrm{C}$ values of the aliphatic carbons $\left(\mathrm{C}_{\mathrm{A}}\right.$ and $\left.\mathrm{C}_{\mathrm{B}+\mathrm{B}^{\prime}}\right)$ of the pristine epoxy resin and nanocomposite samples

\begin{tabular}{lll}
\hline Sample code & $\mathrm{T}_{1 \rho} \mathrm{C}\left(\mathrm{C}_{\mathrm{A}}\right)(\mathrm{ms})$ & $\mathrm{T}_{1 \rho} \mathrm{C}\left(\mathrm{C}_{\mathrm{B}+\mathrm{B}^{\prime}}\right)(\mathrm{ms})$ \\
\hline CE-T0 & $13.2 \pm 0.1$ & $12.3 \pm 0.1$ \\
CE-T5 & $18.9 \pm 0.2$ & $18.0 \pm 0.3$ \\
CE-T5-ex & $20.6 \pm 0.2$ & $21.4 \pm 0.2$ \\
CE-T5-ex-C & $14.0 \pm 0.1$ & $16.4 \pm 0.3$ \\
\hline
\end{tabular}

backbone rearrangements, are capable to slow down a large number of monomer units, suggesting that each NP bonds more than a single monomeric unit.

Furthermore, the maximum increase of $\mathrm{T}_{1 \rho} \mathrm{C}$ was seen for samples CE-T5 and CE-T5-ex, suggesting a homogeneous $\mathrm{TiO}_{2}$ NPs dispersion in these samples. Whereas in the case of CE-T5-ex-C, the likely inhomogeneous filler distribution due to the formation of aggregates does not lead to the same effect on the whole polymeric network resulting in a molecular mobility only slightly affected.

Concerning $T_{\mathrm{CH}}$, the values (in Table 2) are inversely proportional to the magnetization transfer velocity from ${ }^{1} \mathrm{H}$ (abundant spin nucleus) to ${ }^{13} \mathrm{C}$ (diluted spin nucleus). This process is caused by the dipolar interactions through bonds at the particle/matrix interface. Hence, the higher is the proton density around the carbon nuclei, the stronger are the dipolar interactions between them, resulting in smaller $T_{\mathrm{CH}}$ values [33]. In presence of the filler, $T_{\mathrm{CH}}$ values for the carbons $\mathrm{C}_{\mathrm{A}}$ and $\mathrm{C}_{\mathrm{B}+\mathrm{B}^{\prime}}$ of cyclohexyl groups increase, whereas for $\mathrm{C}_{\mathrm{C}}$ decrease. On the one hand, the $T_{\mathrm{CH}}$ increments of $\mathrm{C}_{\mathrm{A}}$ and $\mathrm{C}_{\mathrm{B}+\mathrm{B}^{\prime}}$ carbons indicate a decrease of dipolar interactions between these nuclei and protons, suggesting a decrease of proton density around them. This experimental evidence can be attributed to a decrease of the average molecular weight between two cross-linking points especially in presence of in situ synthesized $\mathrm{TiO}_{2}$ NPs, as also reported in our previous publication [13]. On the other hand, the decrease of the $T_{\mathrm{CH}}$ values for the carbonyl carbon $\left(\mathrm{C}_{\mathrm{C}}\right)$ indicates an increase of proton density in its environment. Taking into account that $\mathrm{C}_{\mathrm{C}}$ does not have any directly bonded hydrogen atom, it is reasonable to assume that the observed increase of proton density can be ascribed by the interaction between $\mathrm{TiO}_{2}$ 's titanols and the polymeric matrix's carbonyl groups $\left(\mathrm{C}_{\mathrm{C}}\right)$ that occurs by means of hydrogen bonds (H-bonds), as schematically represented in Fig. 2.
It is known that as-synthesized titania NPs, by NHSG method, are characterized by hydroxil groups (titanols) [34] on the particle surface and a high temperature calcination leads to their complete elimination by condensation, as reported elsewhere [14]. Therefore, only non-calcined titania NPs are capable to act as cross-linking points among polymeric chains, improving the matrix's mechanical properties, as proposed by our group in previous studies [13-15].

For this reason, the formation of an actual organic/ inorganic 3D network (as schematically represented in Fig. 2) is capable of significantly constraining the polymer's chain mobility. In particular, this is mainly promoted by NPs in situ synthesized by $R S$ method [35], rationalizing the remarkable macroscopic stiffening effect in the rubbery state observed in our published papers [13-15].

Interestingly, the formation of such $\mathrm{H}$-bonds at the interface does not only affect the polymer mechanical properties, but also the filler dispersion, limiting the aggregation that typically occurs with oxide NPs. Some representative TEM micrographs of the prepared samples are reported in Fig. 3, in order to compare the effect of the preparation method on the filler distribution. The sample CE-5T, in Fig. 3a, shows titania domains with sizes between 50 and $300 \mathrm{~nm}$, homogeneously distributed in the polymer matrix. It can be noticed that each domain is composed by small primary NPs with a dimension of $5-10 \mathrm{~nm}$. The homogeneous dispersion is not only due the in situ synthesis that already intrinsically limits the NPs aggregation, but also thanks to the formed $\mathrm{H}$ bonds that have a stabilizing effect on the particles' surface, preventing their aggregation. The TEM micrographs of the sample CE-T5-ex, (Fig. 3b), display that the filler is not homogeneously distributed inside the matrix, showing aggregates with dimensions that range from 50 to $500 \mathrm{~nm}$ and few of them exceed $1 \mu \mathrm{m}$. Even in this case, each aggregate is composed by small primary NPs with dimensions between 5 and $20 \mathrm{~nm}$, visible at higher magnification. Such poor filler dispersion is due to the mechanical mixing, used for preparing the samples, which does not allow achieving complete filler re-dispersion, on the contrary to what was observed in the case of CET5. As expected, even worse filler dispersion is observed in the sample CE-T5-ex-C (Fig. 3c), where big $\mathrm{TiO}_{2}$ agglomerates embedded in the polymeric matrix
Table $2 \mathrm{~T}_{\mathrm{CH}}$ e di $\mathrm{T}_{1 \rho} \mathrm{H}$ values of the ss-NMR signals $\left(\mathrm{C}_{\mathrm{A}}\right.$ and $\mathrm{C}_{\mathrm{B}+}$ ${ }_{B}$ ) related to the pristine epoxy resin and nanocomposite samples

\begin{tabular}{llllll}
\hline Sample code & $\mathrm{T}_{\mathrm{CH}}\left(\mathrm{C}_{\mathrm{A}}\right)(\mathrm{ms})$ & $\mathrm{T}_{\mathrm{CH}}\left(\mathrm{C}_{\left.\mathrm{B}+\mathrm{B}^{\prime}\right)(\mathrm{ms})}\right.$ & $\mathrm{T}_{\mathrm{CH}}\left(\mathrm{C}_{\mathrm{C}}\right)(\mathrm{ms})$ & $\mathrm{T}_{1 \rho} \mathrm{H}\left(\mathrm{C}_{\mathrm{A}}\right)(\mathrm{ms})$ & $\mathrm{T}_{1 \rho} \mathrm{H}\left(\mathrm{C}_{\left.\mathrm{B}+\mathrm{B}^{\prime}\right)(\mathrm{ms})}\right.$ \\
\hline CE-T0 & $181 \pm 10$ & $182 \pm 10$ & $917 \pm 11$ & $6.0 \pm 0.1$ & $5.1 \pm 0.2$ \\
CE-T5 & $241 \pm 12$ & $217 \pm 10$ & $866 \pm 12$ & $8.0 \pm 0.1$ & $7.2 \pm 0.1$ \\
CE-T5-ex & $256 \pm 12$ & $252 \pm 11$ & $773 \pm 11$ & $8.2 \pm 0.1$ & $7.4 \pm 0.1$ \\
CE-T5-ex-C & $267 \pm 11$ & $243 \pm 10$ & $835 \pm 11$ & $8.4 \pm 0.1$ & $7.5 \pm 0.1$ \\
\hline
\end{tabular}


Fig. 2 Schematic illustration of the interactions, through $\mathrm{H}$-bonds, at polymer/ $/ \mathrm{TiO}_{2} \mathrm{NPs}$ interface

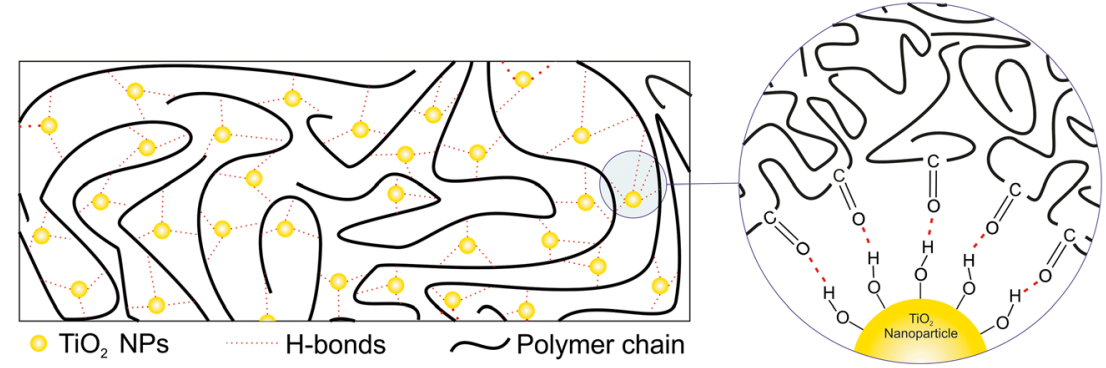

\section{Conclusions}

The presented work reports a comparative study on epoxy resin/ $\mathrm{TiO}_{2}$ nanocomposites prepared by both the reactive suspension method and conventional mechanical mixing method. Solid-state nuclear magnetic resonance investigations revealed the formation of hydrogen bonds, in the samples prepared by the reactive suspension method, at the particle/ matrix interface between the hydroxyl groups on the $\mathrm{TiO}_{2}$ nanoparticles surface and the carboxyl groups of the resin. The same sort of interaction is not observed for composites prepared by means of conventional mechanical mixing of ex
Fig. 3 TEM micrographs at different magnification for the samples. a CE-T5, b CE-T5exand

c CE-T5-ex-C

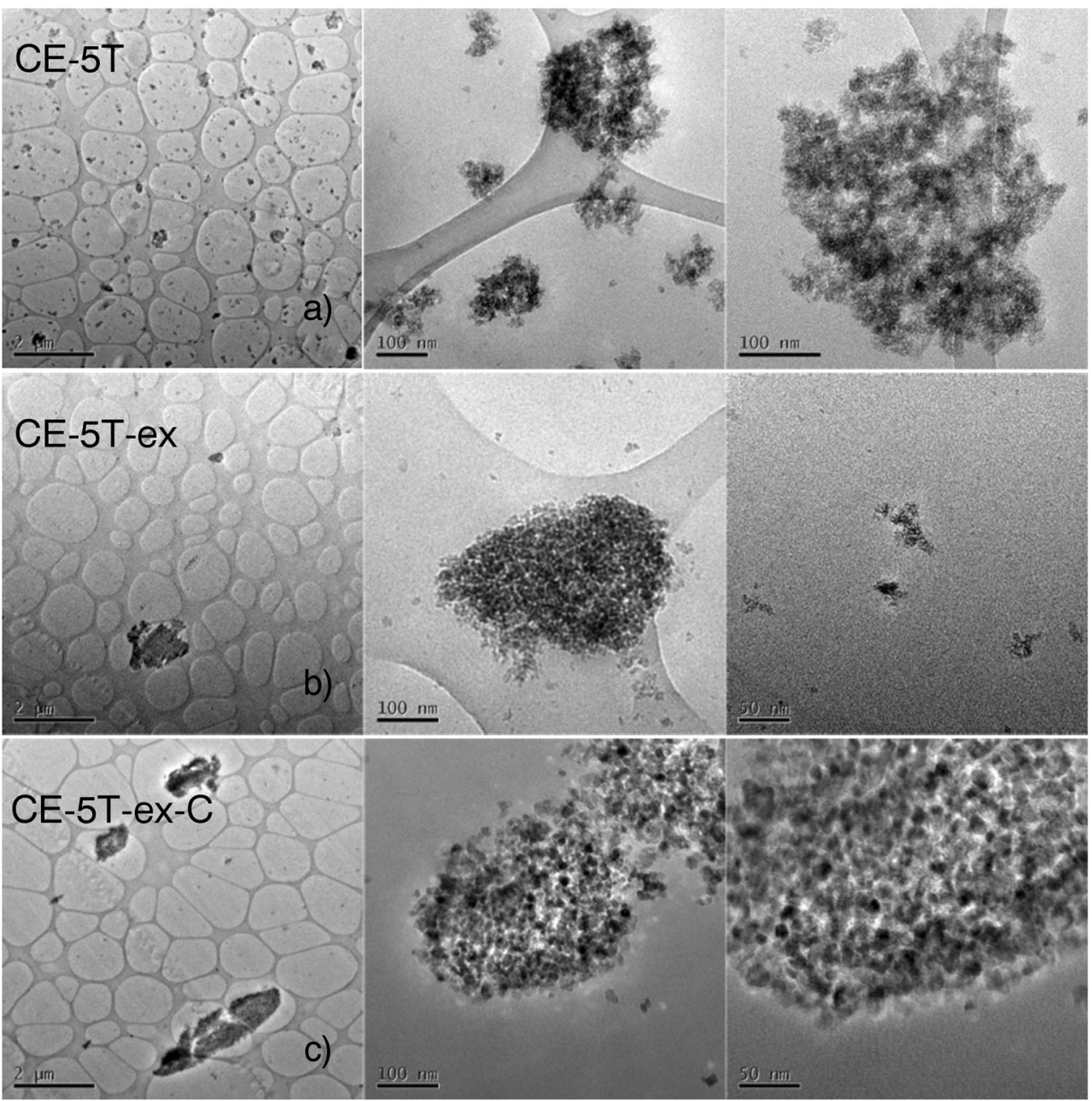


situ synthesized calcined titania. This is rationalized by the elimination of the hydroxyl groups during the calcination process, which prevents the formation of the above-mentioned hydrogen-bonds. Such result represents a direct evidence of our formerly reported theory in which the formed nanoparticles, by reactive suspension method, act not only as a rigid filler embedded in a polymeric matrix, but also as actual crosslinking points among polymer's chains. This is further supported by the results of variable spin lock experiments, which showed that each nanoparticle bonds more than one monomeric unit, therefore acting as "cross-linking densifier" and forming an organic-inorganic network. Finally, transmission electron microscopy investigations showed the influence of the particle/matrix interactions on the dispersion of the filler. In fact, the sample prepared by reactive suspension method showed the best homogeneous filler distribution with a limited aggregation degree thanks to the formation of hydrogen bonds at the polymer/filler interphase that stabilize the nanoparticles' surface limiting the typical aggregation observed in the samples prepared by conventional mixing methods.

\section{Compliance with ethical standards}

Conflict of interest The authors declare that they have no conflict of interest.

Source of funding The author declares no sources of funding.

\section{References}

1. Mallick PK (2000) Particulate and short fiber reinforced polymer composites. In: Zweben C (ed) Comprehensive composite materials. Pergamon, Oxford. doi:10.1016/B0-08-042993-9/00085-1

2. Burnside SD, Giannelis EP (1995) Synthesis and properties of new poly(dimethylsiloxane) nanocomposites. Chem Mater 7(9):15971600. doi:10.1021/Cm00057a001

3. Dasari A, Yu ZZ, Cai GP, Mai YW (2013) Recent developments in the fire retardancy of polymeric materials. Prog Polym Sci 38(9): 1357-1387. doi:10.1016/j.progpolymsci.2013.06.006

4. Vassileva E, Friedrich K (2003) Epoxy/alumina nanoparticle composites. I. Dynamic mechanical behavior. J Appl Polym Sci 89(14): 3774-3785. doi:10.1002/App.12463

5. Bondioli F, Cannillo V, Fabbri E, Messori M (2005) Epoxy-silica nanocomposites: preparation, experimental characterization, and modeling. J Appl Polym Sci 97(6):2382-2386. doi:10.1002/app. 21854

6. Lu XF, Lv XQ, Sun ZJ, Zheng YF (2008) Nanocomposites of poly(L-lactide) and surface-grafted $\mathrm{TiO} 2$ nanoparticles: synthesis and characterization. Eur Polym J 44(8):2476-2481. doi:10.1016/ J.Eurpolymj.2008.06.002

7. Wang QH, Xue QJ, Shen WC, Zhang JY (1998) The friction and wear properties of nanometer $\mathrm{ZrO} 2$-filled polyetheretherketone. J Appl Polym Sci 69(1):135-141. doi:10.1002/(Sici)10974628(19980705)69:1<135::Aid-App16>3.3.Co;2-O

8. Li JH, Hong RY, Li MY, Li HZ, Zheng Y, Ding J (2009) Effects of $\mathrm{ZnO}$ nanoparticles on the mechanical and antibacterial properties of polyurethane coatings. Prog Org Coat 64(4):504-509. doi:10.1016/ j.porgcoat.2008.08.013
9. Crosby AJ, Lee JY (2007) Polymer nanocomposites: the "nano" effect on mechanical properties. Polym Rev 47(2):217-229. doi: 10.1080/15583720701271278

10. Fu SY, Feng XQ, Lauke B, Mai YW (2008) Effects of particle size, particle/matrix interface adhesion and particle loading on mechanical properties of particulate-polymer composites. Compos Part BEng 39(6):933-961. doi:10.1016/J.Compositesb.2008.01.002

11. Ou Y, Yang F, Yu Z-Z (1998) A new conception on the toughness of nylon 6/silica nanocomposite prepared via in situ polymerization. Journal of Polymer Science Part B: Polymer Physics 36 (5):789795. doi:10.1002/(SICI)1099-0488(19980415)36:5<789::AIDPOLB6>3.0.CO;2-G

12. Zhou YX, White E, Hosur M, Jeelani S (2010) Effect of particle size and weight fraction on the flexural strength and failure mode of TiO2 particles reinforced epoxy. Mater Lett 64(7):806-809. doi:10. 1016/J.Matlet.2010.01.016

13. Morselli D, Bondioli F, Sangermano M, Messori M (2012) Photocured epoxy networks reinforced with $\mathrm{TiO}_{2}$ in-situ generated by means of non-hydrolytic sol-gel process. Polymer 53(2):283-290. doi:10.1016/j.polymer.2011.12.006

14. Morselli D, Bondioli F, Sangermano M, Messori M (2014) Epoxy networks reinforced with $\mathrm{TiO}_{2}$ generated by nonhydrolytic sol-gel process: a comparison between in situ and ex situ syntheses to obtain filled polymers. Polym Eng Sci 55(7):1689-1697. doi:10. 1002/pen.24007

15. Morselli D, Bondioli F, Sangermano M, Roppolo I, Messori M (2014) Epoxy resins reinforced with $\mathrm{TiO}_{2}$ generated by nonhydrolytic sol-gel process. J Appl Polym Sci 131(13):40470. doi:10.1002/App.40470

16. Morselli D, Bondioli F, Fiorini M, Messori M (2012) Poly(methyl methacrylate)- $\mathrm{TiO} 2$ nanocomposites obtained by non-hydrolytic sol-gel synthesis: the innovative tert-butyl alcohol route. J Mater Sci 47(19):7003-7012. doi:10.1007/s10853-012-6651-4

17. Morselli D, Messori M, Bondioli F (2011) Poly(methyl methacrylate)- $\mathrm{TiO} 2$ nanocomposite obtained by non-hydrolytic sol-gel synthesis. J Mater Sci 46(20):6609-6617. doi:10.1007/s10853-0115610-9

18. Paderni K, Morselli D, Bondioli F, Luyt AS, Mokhothu TH, Messori M (2013) EPDM rubber reinforced with titania generated by nonhydrolytic sol-gel process. Polym Eng Sci 54(11):25442552. doi:10.1002/pen.23805

19. Sciancalepore C, Bondioli F, Messori M (2016) Non-hydrolytic sol-gel synthesis and reactive suspension method: an innovative approach to obtain magnetite-epoxy nanocomposite materials. J Sol-Gel Sci Techn:1-15. doi:10.1007/s10971-016-4095-Z

20. Sciancalepore C, Bondioli F, Messori M, Barrera G, Tiberto P, Allia P (2015) Epoxy nanocomposites functionalized with in situ generated magnetite nanocrystals: microstructure, magnetic properties, interaction among magnetic particles. Polymer 59:278-289. doi: 10.1016/j.polymer.2014.12.047

21. Niederberger M, Pinna N (2009) Metal oxide nanoparticles in organic solvents: synthesis, formation, assembly and application. Springer, London (UK). doi:10.1007/978-1-84882-671-7

22. Fernandez-Francos X, Foix D, Serra A, Salla JM, Ramis X (2010) Novel thermosets based on DGEBA and hyperbranched polymers modified with vinyl and epoxy end groups. React Funct Polym 70(10):798-806. doi:10.1016/J.Reactfunctpolym.2010.07.008

23. Landel RF, Nielsen LE (1993) Mechanical properties of polymers and composites, Second Edition edn. CRC Press, New York, USA

24. Hartmann SRH, EL (1962) Nuclear double resonance in the rotating frame. American Physical Society 128(5):2042-2053. doi:10. 1103/PhysRev. 128.2042

25. Saladino ML, Martino DC, Floriano MA, Hreniak D, Marciniak L, Strek W, Caponetti E (2014) Ce:Y3A15O12-poly(methyl methacrylate) composite for white-light-emitting diodes. J Phys Chem C 118(17):9107-9113. doi:10.1021/jp412173g 
26. Firetto V, Scialdone O, Silvestri G, Spinella A, Galia A (2010) Copolymerization of vinylidene fluoride and acrylic acid in supercritical carbon dioxide. J Polym Sci Pol Chem 48(1):109-121. doi: 10.1002/pola.23766

27. Udagawa A, Yamamoto Y, Inoue Y, Chujo R (1991) Physicalproperties and photoreactivity of cycloaliphatic epoxy-resins cured by UV-induced cationic polymerization. Polym J 23(9):1081-1090. doi:10.1295/Polymj.23.1081

28. Saladino ML, Motaung TE, Luyt AS, Spinella A, Nasillo G, Caponetti E (2012) The effect of silica nanoparticles on the morphology, mechanical properties and thermal degradation kinetics of PMMA. Polym Degrad Stabil 97(3):452-459. doi:10.1016/j. polymdegradstab.2011.11.006

29. Motaung TE, Luyt AS, Bondioli F, Messori M, Saladino ML, Spinella A, Nasillo G, Caponetti E (2012) PMMA-titania nanocomposites: properties and thermal degradation behaviour. Polym Degrad Stabil 97(8):1325-1333. doi:10.1016/j.polymdegradstab. 2012.05.022

30. Motaung TE, Saladino ML, Luyt AS, Martino DC (2013) Influence of the modification, induced by zirconia nanoparticles, on the structure and properties of polycarbonate. Eur Polym J 49(8):20222030. doi:10.1016/j.eurpolymj.2013.04.019
31. Motaung TE, Luyt AS, Saladino ML, Caponetti E (2013) Study of morphology, mechanical properties, and thermal degradation of polycarbonate-titania nanocomposites as function of titania crystalline phase and content. Polym Composite 34(2):164-172. doi:10. 1002/pc.22389

32. Borsacchi S, Paderni K, Messori M, Toselli M, Pilati F, Geppi M (2014) Insights into shape-memory poly(epsilon-caprolactone) materials by solid-state NMR. Macromolecules 47(11):3544-3552. doi:10.1021/ma5005716

33. Alessi S, Caponetti E, Guven O, Akbulut M, Spadaro G, Spinella A (2015) Study of the curing process of DGEBA epoxy resin through structural investigation. Macromol Chem Phys 216(5):538-546. doi:10.1002/macp.201400510

34. Morselli D, Niederberger M, Bilecka I, Bondioli F (2014) Double role of polyethylene glycol in the microwaves-assisted non-hydrolytic synthesis of nanometric $\mathrm{TiO} 2$ : oxygen source and stabilizing agent. J Nanopart Res 16(10):1-11. doi:10.1007/s11051-014-2645-2

35. Mazzocchetti L, Scandola M, Pollicino A (2008) Study of the organic-inorganic phase interactions in polyester-titania hybrids. Polymer 49(24):5215-5224. doi:10.1016/J.Polymer.2008.09.029 